\title{
Otosclerrosis-an High Risk Factor Of Prolonged Oral Contraceptives
}

\author{
Bandla Narendar Reddy*, Raghunandan and Satish K \\ Baslp Yr III, SDC, India
}

Submission: March 05, 2017; Published: March 24, 2017

*Corresponding author: Bandla Narendar Reddy, Baslp Yr III, SDC, Osmania University, Hyderabad, India, Tel: 8801572737;

Email: narendaraslp@gmail.com

\begin{abstract}
Oral contraceptive has a tremendous usage by the present day life for women to avoid unwanted pregnancy. They experiences physical and emotional symptoms with short time effect but as reported a prolonged usage of these controlled pills has an alteration effect on physical and sensory system. However long b4 work has been done on changing PTA threshold and TTS as a function of OCP, detailed result of the effect is not yet known.
\end{abstract}

Aim: To find out the alteration of hearing sensitivity due to otosclerosis following prolonged usage of OCP.

Methodology: This study included 10 healthy women who are using OCPS minimum of 6 months without any medical complications. This test population were selected based on the inclusion and exclusion criteria. Test battery includes PTA, Speech audiometry, and Impedance audiometry.

Results: The results show from this experimental design that there was a significant change in the hearing threshold following Otosclerosis irrespective of the stages due to the prolonged contraceptive doses.

Discussion: The short experimental study represents a significant hearing alteration, however it was confirmed from both Otolaryngologist and Audiologists that these population represents atypical otosclerosis HL during OCP usage and gets precipitate with prolong usage of these doses. However the degree of HL following OCP is based upon the pathophysiological origin of otosclerosis

\section{Introduction}

Otosclerosis is the disorder of bone growth that affects the stapes and the bony labyrinth of cochlea. Also the bone around the stapes becomes thickened and eventually fuses the bone of the cochlea. This reduces normal sound transmission resulting in conductive deafness. In early stages of otosclerosis the cochlea and the nerve of the hearing are not affected though eventually these too may be involved. Disease processes is characterized by desorption of bone and new spongy formation around the stapes and oval window resulting fixation which leads to conductive loss. Otosclerosis can be seen in both sexes. When gender is compared, Females are more prone to get Otosclerosis due to physiological changes like hormonal and metabolic changes. Otosclerosis is caused due to genetic and nongenetic factors. Genetic factors includes autosomal dominant, autosomal recessive, X \& Y linked [1-6].

By any one of the above genetic factors it is inherited from one generation to other.non genetic factors includes calcification of the Stapedial bone due to which erosion of the bone takes place. Because of that the stapes is fixed into the oval window, which results in reduction of transmission of sound. Reduction of the synovial fluid which is present at the junction of the bones that is mallets, incurs, stapes, due to it reduces the viscosity. Also it has been reported that females during pregnancy are more prone to get otosclerosis due to hormonal alterations. Due to hormonal alterations, there will be impairment in the homeostasis of labyrinth fluids. At this instance if the female user oral contraception to avoid the pregnancy there will be changes in progress of otosclerosis [5,6]. Recent literature reveals that $0.5 \%-1 \%$ i.e. 5 members of the women are affecting with otosclerosis during pregnancy out of 600 pregnancy women however present literature shows the impairment of hearing mechanism. Very few articles have been reporting the incidence of otosclerosis. The present study has been carried out to look the incidence of otosclerosis among the OCP users with reference to impairment of degree of loss.

The use of COC is contraindicated if a woman has experienced deterioration of hearing following otosclerosis during pregnancy 
or previous steroid use. a large cohort did not find any significant associating between COC use and otosclerosis. There have been suggestions that COC can worsen the condition but there is no evidence to support this. Faculty of family planning and reproductive health care otosclerosis is a disorder of hardening of the bones of the middle ear causing progressive hearing loss that is often reversible. Despite extensive searching, the clinical effectiveness unit could not find no information in the literature on the use if contraception in a women with family history of otosclerosis. Women with a family history of otosclerosis who are anxious about the COC may wish to consider the use of progesterone only methods of contraception, an intrauterine or barrier methods. Many cases of otosclerosis are genetic and the disorder affects women twice as men and often worsens rapidly during pregnancy [7].

Even though heredity plays an important role, a significant number of cases arise due to nongenetic causes, which are currently unknown. Clinical otosclerosis is a familial disease which is more frequent among women in their reproductive years. The condition usually aggravated by pregnancy. Endocrinology variables may influence the time of onset and the course of the hearing loss. During the first part of menstrual cycle, body is preparing itself for pregnancy, more estrogen is produced because it makes the lining of the womb thicker so that a fertilized egg can grow in it. During the second part of the cycle more progesterone is produced. This stops the growth of the lining the womb [5-7]. If the egg is not fertilized, the amounts of the two hormones decrease and this makes the lining of the womb breakdown. The lining will be discarded, together with the unfertilized egg as a menstrual breed. If the egg is fertilized, the two hormones will continue to be produced through pregnancy. The presence of high levels of these hormones stops ovaries.

The usage of OCP has an immediate effect on physiology by altering the hormonal system due to which there is an immediate symptom found on auditory vestibular physiology as ear being an organ of sensitive sensory system. Study done by British tinnitus association in oct. 2007 on "women using combined oral contraception, is there any association between its use and otosclerosis?" [8,9], it was found that there is an evidence of detoriation in hearing by usage of OCP. Another study was done by William H. Lippy, MD. Leonard P. Berenholz et al. [10] on ninety four women ( 47 with children and 47 without) were evaluated. Because many of the women had bilateral otosclerosis, the total no. of the ears studied was 128 . The results were found that there is no correlation was found between the no. children and hearing loss. This study was done in 25 may 2005.

\section{Objectives}

So the present study aims at

I. To find the auditory alteration following otosclerosis by pronged usage of OCP
II. To find the degree and type of hearing loss following otosclerosis in prolonged usage of OCP.

\section{Methodology}

This study includes 10 healthy women, with prolonged usage of OCP for minimum of 6 months without any medical complications. The study has been carried out for women of age 26-35yrs based upon inclusion and exclusion criteria

\section{Inclusion criteria include}

i. Minimum usage of OCP for 6 months,

ii. No significant complaint of hearing since childhood.

iii. No family history of hearing loss

iv. No other medical history

\section{Exclusion criteria include}

i. $\quad$ Age more than 35yrs

ii. Usage of combined OCP

iii. OCP used for less than 6 months

iv. Family history of hearing loss

\section{Instrumentation}

Hearing thresholds were obtained using a pure tone audiometer (ALPS AD 2100) calibrated in accordance with American National Standard Institute specifications, speech reception and discrimination scores were obtained by speech audiometry using telugu stimulus, acoustic imittance measures were obtained using a calibrated tympanometry and reflexometry (MICO MA22) and cochlear functions can be measured using a otoacoustic emission (BIOLOGIC ADEAX). The PTA threshold, SRT, SDS were obtained by using calibrated earphones of TDH39 $\mathrm{P}$ and $\mathrm{B} 72$ bone vibrator in a sound treated room.

\section{Procedure}

The subject selection was done from the referrals of gynecologist and pediatrician and the test protocol was followed by an Otolaryngologists examination after confirming non significant or unimpaired Vestibular and cochlear function. Serial audiometry was done on all the cases with prior Case history collection. Screened subjects were subjected to PTA for both Right and Left ears by using TDH 39p headphones and for bone conduction by using B72 bone vibrator. This test is done in a sound treated room with a permissible ambient noise according to ANSI 1999. The subject is instructed according to ASHA guidelines and the threshold were obtain at octave frequencies from 250 to $8000 \mathrm{~Hz}$ for both right and left ears with pure tones as a stimulus. After obtaining AC thresholds, the better ear BC is measured by using bone vibrator at frequencies from 250 to $4000 \mathrm{~Hz}[10,11]$. After obtaining pure tone thresholds, speech thresholds were taken by using speech audiometry speech recognition and speech discrimination threshold by using PB 
words and spondee words in Telugu. After that the subjects were undergone acoustic imittance values by using immitance audiometry and reflexometry to rule out middle ear pathology. The subject is instructed not to swallow and to hold breath during the test and the results were obtained by using probe tip. Cochlear functions for $\mathrm{OHC}$ were checked by using screening OAE with clicks as a stimulus.

\section{Results}

The present experimental study shows a significant change in hearing threshold by otosclerosis following prolonged usage of OCP. The PTA thresholds were ranging from minimal to moderately severe level for all 10 subjects. The degree of 6 subjects were ranging tending more towards minimal to mild level i.e16 to $40 \mathrm{~dB}$ and the remaining 4 subjects has moderately severe level i.e. 55 to $70 \mathrm{~dB}$ (Table 1). Speech audiometry test results were correlating to PTA for all the subjects. Tympanometry test results shows that there is a presence of various types of tympanogram based upon usage of medication. "As" type tympanogram is evident in 5 subjects, suggesting fixation of stapes foot plate to the oval window and " $\mathrm{A}$ " type tympanogram is evident in remaining 5 subjects because of absence of middle ear pathology as reported by the ENT but there is a extra growth on the bony capsule of the cochlea due to which it causes SNHL in 4 cases. Reflexometry results were based upon the degree of the hearing loss. For stapedial otosclerosis, the degree is ranging from minimal to mild level, so that the ipsilateral reflexes were present and contralateral reflexes were elevated.

Table 1: The degree of 6 subjects were ranging tending more towards minimal to mild level i.e16 to $40 \mathrm{~dB}$ and the remaining 4 subjects has moderately severe level i.e. 55 to $70 \mathrm{~dB}$.

\begin{tabular}{|c|c|c|c|c|c|c|c|c|c|c|c|c|c|}
\hline \multirow{3}{*}{ Se. No } & \multirow{2}{*}{\multicolumn{2}{|c|}{ Pta }} & \multicolumn{4}{|c|}{ Speech Audiometry } & \multirow{2}{*}{\multicolumn{2}{|c|}{ Tympanometry }} & \multirow{2}{*}{\multicolumn{2}{|c|}{$\begin{array}{c}\text { Reflexology } \\
\text { try }\end{array}$}} & \multirow{2}{*}{\multicolumn{2}{|c|}{ Oae }} & \multirow{3}{*}{ Diagnosis } \\
\hline & & & \multirow{2}{*}{$\begin{array}{c}\text { SRT } \\
\text { Rt }\end{array}$} & \multirow[b]{2}{*}{ Lt } & \multirow{2}{*}{$\begin{array}{c}\text { SDS } \\
\text { Rt }\end{array}$} & \multirow[b]{2}{*}{ Lt } & & & & & & & \\
\hline & Rt. & Lt. & & & & & Rt. & Lt. & Rt. & Lt. & Rt. & Lt. & \\
\hline 1 & $35 \mathrm{~dB}$ & $10 \mathrm{~dB}$ & $45 \mathrm{~dB}$ & $20 \mathrm{~dB}$ & $90 \%$ & $95 \%$ & As & $\mathrm{A}$ & $\mathrm{E}$ & $\mathrm{P}$ & $\mathrm{P}$ & $\mathrm{P}$ & Stapedial otosclerosis \\
\hline 2 & $35 \mathrm{~dB}$ & $30 \mathrm{~dB}$ & $45 \mathrm{~dB}$ & $40 \mathrm{~dB}$ & $80 \%$ & $85 \%$ & As & As & $P$ & $\mathrm{P}$ & $\mathrm{A}$ & A & Mixed otosclerosis \\
\hline 3 & $75 \mathrm{~dB}$ & $65 \mathrm{~dB}$ & $85 \mathrm{~dB}$ & $75 \mathrm{~dB}$ & $75 \%$ & $85 \%$ & $\mathrm{~A}$ & $\mathrm{~A}$ & $\mathrm{~A}$ & $\mathrm{~A}$ & $\mathrm{~A}$ & $\mathrm{~A}$ & Cochlear otosclerosis \\
\hline 4 & $25 \mathrm{~dB}$ & $30 \mathrm{~dB}$ & $35 \mathrm{~dB}$ & $40 \mathrm{~dB}$ & $85 \%$ & $80 \%$ & As & As & $\mathrm{P}$ & $\mathrm{P}$ & $\mathrm{P}$ & $\mathrm{P}$ & Stapedial otosclerosis \\
\hline 5 & $25 \mathrm{~dB}$ & $25 \mathrm{~dB}$ & $35 \mathrm{~dB}$ & $35 \mathrm{~dB}$ & $85 \%$ & $85 \%$ & As & As & $\mathrm{P}$ & $\mathrm{P}$ & A & A & Mixed otosclerosis \\
\hline 6 & $30 \mathrm{~dB}$ & $25 \mathrm{~dB}$ & $40 \mathrm{~dB}$ & $35 \mathrm{~dB}$ & $85 \%$ & $95 \%$ & $\mathrm{~A}$ & $\mathrm{~A}$ & $\mathrm{P}$ & $\mathrm{P}$ & $\mathrm{P}$ & $\mathrm{P}$ & Tympanic otosclerosis \\
\hline 7 & $55 \mathrm{~dB}$ & $55 \mathrm{~dB}$ & $65 \mathrm{~dB}$ & $65 \mathrm{~dB}$ & $80 \%$ & $85 \%$ & A & A & A & A & $\mathrm{A}$ & $\mathrm{A}$ & Cochlear otosclerosis \\
\hline 8 & $70 \mathrm{~dB}$ & $50 \mathrm{~dB}$ & $80 \mathrm{~dB}$ & $60 \mathrm{~dB}$ & $70 \%$ & $80 \%$ & A & $\mathrm{A}$ & A & A & $\mathrm{A}$ & $\mathrm{A}$ & Cochlear otosclerosis \\
\hline 9 & $30 \mathrm{~dB}$ & $20 \mathrm{~dB}$ & $40 \mathrm{~dB}$ & $30 \mathrm{~dB}$ & $85 \%$ & $95 \%$ & As & As & $\mathrm{P}$ & $\mathrm{P}$ & $\mathrm{A}$ & $\mathrm{A}$ & Mixed otosclerosis \\
\hline 10 & $60 \mathrm{~dB}$ & $80 \mathrm{~dB}$ & $70 \mathrm{~dB}$ & $90 \mathrm{~dB}$ & $80 \%$ & $70 \%$ & $\mathrm{~A}$ & $\mathrm{~A}$ & A & A & A & A & Cochlear otosclerosis \\
\hline
\end{tabular}

For cochlear otosclerosis, the degree is ranging to moderately severe, so that the reflexes were absent in both ipsilateral and contralateral pathway. For mixed otosclerosis, the degree is ranging to mild level, so that the ipsilateral reflexes were present and contralateral reflexes were elevated. For tympanic otosclerosis, the degree is ranged to minimal level, so that the reflexes is present in both ipsilateral and contralateral pathway.OAE results were supporting the study showing an effect of OCP on Inner Ear. if the hearing loss exceeds more than $50 \mathrm{~dB}$ then the OAE's will be absent. In this study the selected subjects were tested by using OAE. The results were shown as, OAE's were evident for 3 subjects and absent for 7 subjects. As the conclusion, 2 are diagnosed as Stapedial otosclerosis, 4 are diagnosed as cochlear otosclerosis, 1 is diagnosed as tympanic otosclerosis, 3 are diagnosed as a mixed otosclerosis.

\section{Discussion}

By concluding the above result we find that usage of prolonged OCP, women are more prone to get otosclerosis. Audio logical results shows that the degree of the hearing loss of the selected 10 subjects is ranging from minimal to severe hearing loss i.e. 16 to $90 \mathrm{~dB}$. If we taken as a mean threshold for all subjects, the mean threshold for all subjects, the mean threshold for rt ear is $44 \mathrm{~dB}$ and for lt ear is $39 \mathrm{~dB}$.Tympanometry results found that there is an of "As" type tympanogram in 50\% subjects and "A" type tympanogram in remaining 50\% subjects. OAE results found that there is a presence of normal cochlear function in $30 \%$ subjects and the remaining $70 \%$ subjects has detoriation in cochlear function. Based upon these results we diagnosed them as otosclerosis. As the results vary for each subject out of 10 subjects, we diagnosed them with different types of otosclerosis like stapedial otosclerosis for $20 \%$ subjects, cochlear otosclerosis for $40 \%$ subjects, tympano otosclerosis for $10 \%$ subject and mixed otosclerosis for $30 \%$ subjects.

This present study with limited controlled sample has shown that the OCP usage has a significant impact on inner ear along with OTOSCLEROSIS of various types irrespective of place.

\section{Clinical Implication}

At present day situation, it is of a greater challenge to the audiologist to manage the problem of women using oral 
contraceptives. It's the audiologist's role to council the OCP users to

i. Reducing the dosage of OCP

ii. OCP users who has signs of hearing loss had follow up with the audiologist

iii. Making awareness that if they use OCP there are prone to get hearing loss

\section{Limitations}

Selected subjects for this study is limited with types of medicine not controlled. So this study can be carried out with a large number of samples to know the variability of otosclerosis with OCP usage.

\section{References}

1. Aitkin L (1990) The auditory cortex; structural and functional bases of auditory perception. Springer 109-120.

2. COX J R (1980) Hormonal influence on auditory function. Ear and Hearing 1(4): 219-222.
3. Davis M J, Ahroon W A (1982) Fluctuations in susceptibility to noiseinduced temporary threshold shift as influenced by the menstrual cycle. Journal of Auditory Research 22(3): 173-187.

4. Frank E, Jennifer B, Linda G, Elena Zaidan, Jeffrey Weihing, et al. (2007) Central deafness: An audiological case study. International journal of audiology 46(8): 433-441.

5. Henry K R (1980) Effects of noise, hypothermia and barbiturate on cochlear electrical activity. Audiology 19: 44-56.

6. Lotvin BR (1996) Anticoncepcion hormonal oral Y metabalismo de los Hidratos de carbon. Ginecol obstet mex 64(5): 198-200.

7. Miller MH, Gould WJ (1967) Fluctuating sensorineural hearing impairment associated with the menstrual cycle. Journal of Auditory Research 7: 373-385.

8. Robert W (1980) audiology for the physicians 201-208

9. Rybak LP (1995) Metabolic disorders of the vestibular system. Otolaryngol Head neck surg 112(1): 128-132.

10. Stover L, Michel P, Stephen T (1996) Towards optimizing the clinical utilities of DPOAE measurements. Acoustic society of America 100: 956- 967.

11. Tyler S L, Woodall G M (1982) Female health and gynecology: Across the lifespan. Bowie MD Robert J Brady Co.

\section{Your next submission with Juniper Publishers will reach you the below assets}

- Quality Editorial service

- Swift Peer Review

- Reprints availability

- E-prints Service

- Manuscript Podcast for convenient understanding

- Global attainment for your research

- Manuscript accessibility in different formats ( Pdf, E-pub, Full Text, Audio)

- Unceasing customer service

Track the below URL for one-step submission https://juniperpublishers.com/online-submission.php 